Thorax, 1980, 35, 721-724

\title{
Editorial
}

\section{What is the best treatment for early operable small cell carcinoma of the bronchus?}

Small or oat cell carcinoma of the bronchus behaves in a uniform manner and its microscopic appearance has a similar uniform pattern. The latter is highly distinctive and has been fully described by Azzopardi. ${ }^{1}$ Small cells varying in shape from nearly round to fine spindles are the main constituents. Approximately $95 \%$ of the patients are male and $85 \%$ are smokers. The overall incidence is about $36 \%$ of all lung cancers. ${ }^{2}$ The proportion of these growths in surgically excised specimens is much lower as they are highly malignant and often inoperable when first seen. In a series of 2430 patients subjected to thoracotomy between 1950 and 1978 for bronchial carcinoma there were 240 small cell tumours $(10.9 \%){ }^{3}$

The prognosis for the advanced case presenting with metastases is very poor and the expectation of life short. It is true to say that the attitude of many workers dealing with early cases is equally pessimistic. That such pessimism is soundly based is evident from the 1969 Medical Research Council report $^{4}$ of a comparative trial of surgery alone and radiotherapy alone for the primary treatment of this condition, the figures for surgery giving a survival of $3 \%$ and for radiotherapy $7 \%$, both figures at four years. The advice is proffered by the MRC that "a patient with oat cell carcinoma on bronchoscopic biopsy should be advised to submit to radiotherapy rather than surgery." This advice was reinforced by their 10-year follow-up. ${ }^{5}$ There were no survivors in 71 patients randomly allocated to surgery, and three out of 73 patients survived at five years in the radical radiotherapy group.

This pessimism was called into question by Bates et $a l^{6}$ reporting the results of 29 patients treated by preoperative Cobalt radiotherapy and radical surgery. Of 18 patients in whom both the biopsy and surgical specimens showed oat cell carcinoma five $(27 \%)$ had survived between four and eight years at the time of writing. A further paper from the same hospital ${ }^{7}$ updated these results, reporting eight out of $45(17 \%)$ patients

Address for reprint requests: Victor Levison, Department of Radiotherapy and Oncology, North Middlesex Hospital, Edmonton, London N18 1QX. alive and well at four years, again where both the biopsy and surgical specimens showed oat cell carcinoma. A similar more optimistic view was put forward by Shore and Paneth ${ }^{8}$ who treated 40 patients with operable small cell carcinoma by resection only and no radiotherapy. Eleven patients were alive at the time of reporting, 10 having survived five years or more, and the overall five-year survival rate was $25 \%$.

Although my purpose here is to consider treatment of the early case, it is necessary at this juncture to review recent developments in the management of the patient with advanced disease, who may present with distant metastases, to see whether the lessons learned from these can be applied to the early case. Intensive preoperative investigation of apparently early localised operable disease by bone, brain, and liver scanning, bone marrow biopsy, and whole lung tomography will serve to exclude those in whom gross dissemination has already taken place, thus avoiding an unjustified thoracotomy. These tests will not demonstrate micro-metastases, which are already present in most patients, and are the cause of death in a very high percentage soon after apparently successful local treatment by surgical resection or irradiation or both. Many papers over recent years testify to the efforts being made to treat undetectable micro-metastases by adjuvant chemotherapy after surgery for apparently early operable malignant disease, particularly in breast cancer. ${ }^{9-10}$ The claims for an improved cure rate and increased lifespan in breast cancer are disputed by Powles et al. ${ }^{11}$ Powles' paper, however, also reinforces the already well-known fact that in Hodgkin's disease a progressive prolongation of survival is observed with new treatment techniques. Small cell carcinoma of the bronchus is a highly radiosensitive, even if not a radiocurable tumour as is Hodgkin's disease, and it would seem reasonable to expect the same response to these treatment techniques.

Johnson et al ${ }^{12}$ described a regime of intensive cyclical chemotherapy (cyclophosphamide, vincristine, and doxorubicin) in small cell carcinoma. This was administered concurrently with radio- 
therapy of bulk disease and whole brain irradiation, the treatment extending over 12 weeks. Complete clinical remissions occurred in 20 out of 21 patients with unresectable tumours, 10 of whom had distant extrathoracic spread initially. Survival was prolonged and nine out of 11 patients with mediastinal or supraclavicular lymph nodes, or pleural effusions, or all three remained diseasefree for a mean of 10 months. The median survival was 11 months for those with extrathoracic disease. The toxicity of this regime was considerable. A similar approach was described by Greco et $a l^{13}$ who reported complete remission in 15 out of 16 patients with limited stage disease treated by chemotherapy (Cyclophosphamide, doxorubicin, and vincristine), radiotherapy, and whole brain irradiation. Twelve patients remained well and disease-free 12 months after starting treatment. The toxicity of their regime was less, the most serious complication being transient neutropenia.

Can the pattern of response demonstrated in the inoperable patient be applied to the treatment of the apparently early case in whom radical surgery with or without radiotherapy has been carried out, but who is likely to succumb in a short time from undetected micro-metastases?

The currently available treatments for operable small cell carcinoma of the bronchus can be summarised under the following headings.

\section{SURGERY ALONE}

The two MRC reports $\left({ }^{4}{ }^{5}\right)$ give a survival of three and $0 \%$ at four and five years respectively.

\section{RADIOTHERAPY ALONE}

The two MRC reports $\left({ }^{4}{ }^{5}\right)$ give a survival of $7 \%$ and $4.1 \%$ at four and five years respectively.

\section{CHEMOTHERAPY ALONE}

Einhorn et $a l^{14}$ treated four patients with limited disease with chemotherapy (doxorubicin, cyclophosphamide, bleomycin, and vincristine) alone. Two showed a complete response, and three lived longer than one year.

\section{SURGERY AND RADIOTHERAPY}

Four-year survival figures vary from $17 \cdot 7 \%^{7}$ to $25 \% .{ }^{6}$ The numbers reported are small, no alternative method of treatment was attempted, and no statistical analysis was possible. It may well be that the improved survival figures are a chance finding and of no statistical validity. It is important to note in considering this treatment combination that all the long-term (four year) survivors in both these papers were in the group given the lower dose of 1750 rad Cobalt irradiation in sevę daily treatments. There were no survivors in the group given $2500 \mathrm{rad}$ in 10 daily treatments. The were no serious postoperative complications either group attributable to the radiation.

\section{RADIOTHERAPY AND CHEMOTHERAPY}

Livingstone et $a l^{15}$ reported a $25 \%$ survival at twf years with radiotherapy and chemotherapy (dox) rubicin and cyclophosphamide). The combined modality programme appeared to be of real benefit to patients with limited disease, as compared t $\vec{\theta}$ the historical controls who had radiotherapy alone Wittes $e t a^{16}$ reported a median survival of $1 z$ months in limited disease treated by radiotherap and monthly cyclical chemotherapy (cyclophosphamide, doxorubicin, vincristine, and methotrexate).

SURGERY, RADIOTHERAPY, AND CHEMOTHERAPY

There is scant published reference to this com bination. Hayata ${ }^{17}$ reporting a series of 1167 patients of all types treated in this way, commento that it was of proven value in prolonging surviva in advanced though resectable cases. Mandelbaur et $a l^{18}$ reported one survivor at two years in three patients so treated (doxorubicin, cyclophospha mide, and vincristine) with the addition of prophy를 lactic whole brain irradiation. My own experience of the addition of chemotherapy (CCNU, metho trexate, and cyclophosphamide) to preoperative radiotherapy and radical surgery was that tho drugs produced an unacceptable morbidity and haf to be abandoned. It may be that if a less toxic drug combination were used it would be acceptable

\section{SURGERY AND CHEMOTHERAPY}

There are few publications on this combination Shields et $a^{19}$ reported a trial of 417 patients with bronchial cancer of all types randomised into threo groups after resection. No benefit was shown at five years in the two groups receiving chemog therapy (cyclophosphamide, and cyclophosphamideu alternating with methotrexate) as compared to the control group receiving no drugs. Long-term ado juvant chemotherapy with mitomycin $\mathrm{C}$ is reporte as improving survival rates after resection. ${ }^{20}$

In order to refute the current pessimistic attic tude to treatment which follows the proven diag nosis of small cell cancer of the lung, even whero it appears after full investigation to be early an operable, it is essential that a clinical trial bब mounted to show which of the available treato ments offers the best hope of long-term survivar and cure. It is neither necessary nor practicable 
to include each treatment modality listed above as a separate arm of such a trial. If this were to be attempted the time required to collect the numbers of patients would be so long that an answer would take many years to appear. Moreover the organisation of such a trial would be difficult and unwieldy by virtue of its size. It is logical to accept that the treatment of this disease by radiotherapy alone and surgery alone has been adequately tested by the Medical Research Council trial, and that no advantage would accrue from repeating this work. It is unlikely that chemotherapy alone with the drugs at present available would be an acceptable treatment to the surgeon or radiotherapist for early operable disease.

In view of the apparently favourable results reported in early disease by Bates $^{6}$ and Levison, ${ }^{7}$ and the remission of advanced metastatic disease with cyclical chemotherapy alone, it would seem reasonable to postulate that the most optimistic approach would be by a combination of preoperative low dose radiotherapy, radical surgery, and subsequent cyclical combination chemotherapy. The chemotherapy must not produce an unacceptable morbidity, or reduce the quality of life. If this is accepted as one arm of a clinical trial what are the other arm or arms to be?

Chemotherapy could be added to either surgery or radiotherapy. Much work has been carried out with the combination of chemotherapy and radiotherapy in small cell tumours and this has been fully reviewed by Livingston ${ }^{21}$ who concludes that the combination is superior to radiotherapy alone in limited disease. Increasing interest is being shown at the present time in the advantage of surgical "debulking" before chemotherapy. Although much of this work is being carried out in the treatment of ovarian cancer, ${ }^{22}$ the logic behind it is equally applicable to the treatment of small cell cancer. Thus the other arm could be surgery and chemotherapy.

It is necessary to consider here the frequency of cerebral metastases in small cell carcinoma, and prophylactic whole brain irradiation has been advocated as a routine measure. In a randomised comparison of patients presenting with no clinical evidence of brain metastases, Weiss et $a l^{23}$ reported significantly fewer CNS relapses in those given whole brain irradiation than in those not so treated, although the median survival of 8.5 months was unaffected. It would, therefore, seem logical to test whether the addition of prophylactic whole brain irradiation would further improve survival.

I would therefore suggest that a multicentre clinical trial be organised to determine the best treatment for early operable small cell carcinoma of the bronchus. The treatment would be decided by random selection from one of the following groups: (1) preoperative low dose radiotherapy, radical surgery, and chemotherapy; (2) preoperative low dose radiotherapy, radical surgery, chemotherapy, and whole brain irradiation; (3) radical surgery and chemotherapy; (4) radical surgery, chemotherapy, and whole brain irradiation.

Large numbers of patients will be required if we are to detect a relatively small but clinically worthwhile advantage in one of the treatments. ${ }^{24}$ Freedman ${ }^{25}$ suggests that three years is about the maximum time for entry into a trial which should be accepted at the planning stage. Bearing in mind that operable small cell carcinoma of the bronchus is uncommon, it is essential that as many centres as possible take part, and that the trial be on a national basis. It is unlikely that enough patients could be collected to produce a clear answer to this vexed and mortal problem unless the majority of thoracic surgeons and radiotherapists were willing to co-operate.

\section{VICTOR LEVISON Department of Radiotherapy and Oncology North Middlesex Hospital London}

\section{References}

1 Azzopardi JG. Oat cell carcinoma of the bronchus. J Pathol Bacteriol 1959; 78:513-9.

2 Bryson CC, Spencer H. Carcinoma of the bronchus. A clinical and pathological survey of 866 cases. $Q J$ Med 1951; 20(NS): 173-86.

3 Bates M, Hunterian Lecture. Surgical treatment of bronchial carcinoma 1950-1978. Ann $R$ Coll Surg 1980; in press.

4 Miller AB, Fox W, Tall R. Five year follow-up of the Medical Research Council comparative trial of surgery and radiotherapy for the primary treatment of small or oat-celled carcinoma of the bronchus. Lancet 1969; 2:501-5.

5 Fox W, Scadding JG. Medical Research Council comparative trial of surgery and radiotherapy for primary treatment of small-celled or oat-celled carcinoma of bronchus. Lancet 1973; 2:63-5.

6 Bates M, Hurt R, Levison V, Sutton M. Treatment of oat-cell carcinoma of bronchus by preoperative radiotherapy and surgery. Lancet 1974; 1:1134-5.

7 Levison V. Pre-operative radiotherapy and surgery in the treatment of oat cell carcinoma of the bronchus. Clin Radiol 1980; 31:345-8.

8 Shore DF, Paneth M. Survival after resection of 
small cell carcinoma of the bronchus. Thorax 1980 ; in press.

9 Fisher B, Slack N, Katrych D, Wolmark N. Ten year follow-up results of patients with carcinoma of the breast in a co-operative clinical trial evaluating surgical adjuvant chemotherapy. Surg Gynaecol Obstet 1975; 140:528-34.

10 Bonadonna G. 1980. Adjuvant chemotherapy of breast cancer. Br J Hosp Med 1980; 23:40-53.

11 Powles TJ, Smith IE, Ford HT, Coombes RC, Jones M, Gazet J-C. Failure of chemotherapy to prolong survival in a group of patients with metastatic breast cancer. Lancet 1980; 1:580-2.

12 Johnson RE, Brereton HD, Kent CH. Small-cell carcinoma of the lung: attempt to remedy causes of past therapeutic failure. Lancet 1976; 2:289-91.

13 Greco FA, Richardson RL, Schulman SF, Stroup S, Oldham RK. Treatment of oat cell carcinoma of the lung. Complete remissions, acceptable complications and improved survival. Br Med J 1978; 2:10-11.

14 Einhorn LH, Fee WH, Farber MO, Livingston RB, Gottlieb JA. Improved chemotherapy for small cell undifferentiated lung cancer. JAMA 1976; 235:1225-9.

15 Livingston RB, Moore TN, Heilbrun L et al. Small-cell carcinoma of the lung: combined chemotherapy and radiation: a south west oncology group study. Ann Intern Med 1978; 88: 194-9.

16 Wittes RE, Hopfan S, Hilaris B, Golbey RB, Melamed M, Martini N. Oat cell carcinoma of the lung. Combination treatment with radio- therapy and cyclophosphamide, adriamycin, vine cristine and methotrexate. Cancer 1977; 40:653-9.을

17 Hayata $Y$, Funatsu $\mathrm{H}$, Aida M, Kawachi $\mathrm{T}^{\mathrm{s}}$ Nogawa M. Surgical treatment for advanced cases of lung cancer. Japan J Thorac Surg 1977; 30 626-33.

18 Mandelbaum I, Williams SD, Hornback NB JoР BT, Einhorn LH. Combined therapy for small cell undifferentiated carcinoma of the lung. \& Thorac Cardiovasc Surg 1978; 76:292-6.

19 Shields TW, Humphrey EW, Eastridge CE, Keehư RJ. Adjuvant cancer chemotherapy after resecer tion of carcinoma of the lung. Cancer 1977; 40:2057-62.

20 Okamoto T, Katsuki H. Surgical treatment and adjuvant anti-cancer chemotherapy for advance $\bar{b}$ bronchogenic carcinoma. Japan J Thorac Surg 1977; 30:561-6.

21 Livingston RB. Treatment of small cell caro cinoma: evolution and future directions. Semiñ Oncol 1978; 5:299-308.

22 Editorial. Cancer of the ovary. Br Med J 1979; 2:687-8.

23 Weiss RB. Small-cell carcinoma of the lung? therapeutic management. Ann Intern Med 1978: 88:522-31.

24 Peto R, Pike MC, Armitage P et al. Design and analysis of randomized clinical trials requiring prolonged observation of each patient. I. Intro응 duction and design. Br J Cancer 1976; 34:585-612?

25 Freedman L. Problems involved in the multi centre studies of cancer treatment. Cancer Topic. 1980; 2:10-11. 